Fecha de recepción: junio 2020 Fecha de aceptación: julio 2020 Versión final: septiembre 2020

\section{Chantal Montellier y Ah!nana. El debut del feminismo en el cómic europeo}

Montserrat Terrones ${ }^{(1)}$

Resumen: Chantal Montellier, autora clave del feminismo en el cómic no solo francobelga sino que también europeo y mundial, tiene una trayectoria extensa y coherente como autora comprometida, que va más allá de su posicionamiento en cuanto a su discurso gráfico y que la ha conducido a participar en diferentes iniciativas únicas. En efecto, Chantal Montellier participó en la creación sin parangón de la revista Ah!nana, primera y efímera revista de cómic feminista en Francia en la década de los 70. Montellier es, además, una de las fundadoras de la Association Artémisia, la primera asociación de difusión del cómic creado por mujeres existente en Europa, la cual se ha convertido en la fuente de inspiración de experiencias similares en otros países. En este artículo recorreremos la trayectoria artística de Montellier y su compromiso político y feminista, la experiencia única de Ah!nana y sus vínculos con el discurso del feminismo radical y buscaremos a las herederas de ambos en el cómic actual, en las figuras de la sueca Liv Strömquist y la alemana Ulli Lust.

Palabras clave: Chantal Montellier - cómic - feminismo - interseccionalidad - Ah!nana.

[Resúmenes en inglés y portugués en las páginas 202-203]

${ }^{(1)}$ Facultat d'Informació i Mitjans Audiovisuals. Universitat de Barcelona.

Chantal Montellier es uno de los referentes del feminismo en el cómic europeo sólo superado por la figura de Claire Brétecher. Su propia trayectoria como dibujante, siendo una de las primeras mujeres autoras de cómic en Francia, el contenido de sus cómics, su posicionamiento público criticando la deriva sexista de una parte de la producción de revistas de bande dessinée que utilizó el cuerpo de la mujer como reclamo comercial y, finalmente, su activismo feminista con la cocreación de la asociación y el premio Artémisia ${ }^{1}$, la convierten en un pilar indiscutible del feminismo en cómic. Sin embargo, su obra parece haber caído en el olvido, sin haber llegado nunca a ser popular. Apenas se encuentra presente en los catálogos editoriales europeos en la actualidad, a pesar de haber sido traducida a varias lenguas en los 80, entre ellas el castellano. Lo mismo sucede con la revista Ah!nana "fait pas et pour les femmes". Una experiencia única, militante y limitada en el tiempo, prác- 
ticamente desconocida en la actualidad fuera de Francia, y en la que Chantal Montellier también participó.

Esta situación nos lleva a preguntarnos qué ha quedado del legado de Chantal Montellier y del primer feminismo en el cómic europeo. En este artículo dedicaremos un primer apartado a recorrer y analizar el discurso de la obra de Chantal Montellier y a situarla en su contexto. En el segundo bloque, describiremos la experiencia feminista más radical que ha tenido lugar en el cómic europeo, la revista Ah!nana, y sus vínculos con el feminismo radical de la segunda ola. Finalmente, en el tercer apartado, intentaremos esclarecer la existencia o no de una corriente no articulada de creación engagé por parte de autoras que retoman, tal vez sin saberlo, el camino iniciado hace más de tres décadas por Chantal Montellier.

\section{El cometa solitario llamado Chantal Montellier}

Antes de entrar en detalle en la obra de Chantal Montellier, haremos una breve mención a la representación de la mujer en la bande dessinée en esos años, la cual se puede resumir como una situación "d'une absence relative de l'heroïne dans la plupart des albums, et d'une représentation stéréotypée de la femme" (Boy, 2009, p. 97). Por ejemplo, si tomamos como epítome de toda la tradición francobelga la obra Tintin, de Hergé, veremos que en el total de la obra no aparecen más que unos 40 personajes femeninos que tienen, además, profesiones de baja calificación y consideración social, como por ejemplo porteras o mujeres de la limpieza y que sólo aparecen en una o dos viñetas con la salvedad del personaje de Castafiore (Macary, 2004). Los principales roles atribuidos a los personajes femeninos (por autores masculinos) son madres de familia en los cómics costumbristas, la eterna novia en los cómics de aventuras, secretarias y porteras, mujeres objeto, enemigas, mujeres de la limpieza y amas de casa, a menudo ambas con un carácter insoportable. Entre 1970 y 1975 solamente se publicaron unas 20 series de cómic protagonizadas por mujeres, entre ellas la protagonizada por Julie Bristol, de Chantal Montellier (Macary, 2004).

Montellier (1947) inició su carrera de dibujante en 1972 en publicaciones sindicalistas y en la prensa política de extrema izquierda como L'Unité, L'Humanité, Révolution, Marianne, etc., la cual era especialmente prolífica en los años 60 y 70. En concreto, la primera publicación la hizo en L'Humanité Dimanche. Para hacernos una idea del tono de Montellier en esos momentos, destacaremos, sin embargo, la publicación realizada en L'Unité con título Consultations gynécologiques au lendemain de la loi Veil. Ésta trataba sobre el tema del aborto en un momento en que se estaba manteniendo un agitado debate social sobre la ley Veil, que proponía la despenalización de éste (Boy, 2009). La ley Veil reconocía el derecho a la abstención de practicar el aborto por razones de conciencia por parte de los profesionales. En la Figura 1, podemos ver como Chantal Montellier retrata el constante estado de indefensión y de subyugación de la mujer, que aún y tener una ley a favor de su derecho al aborto, aún no tiene un control total sobre su cuerpo y está a expensas de decisiones externas, normalmente tomadas por hombres que detentan el poder ${ }^{2}$. 


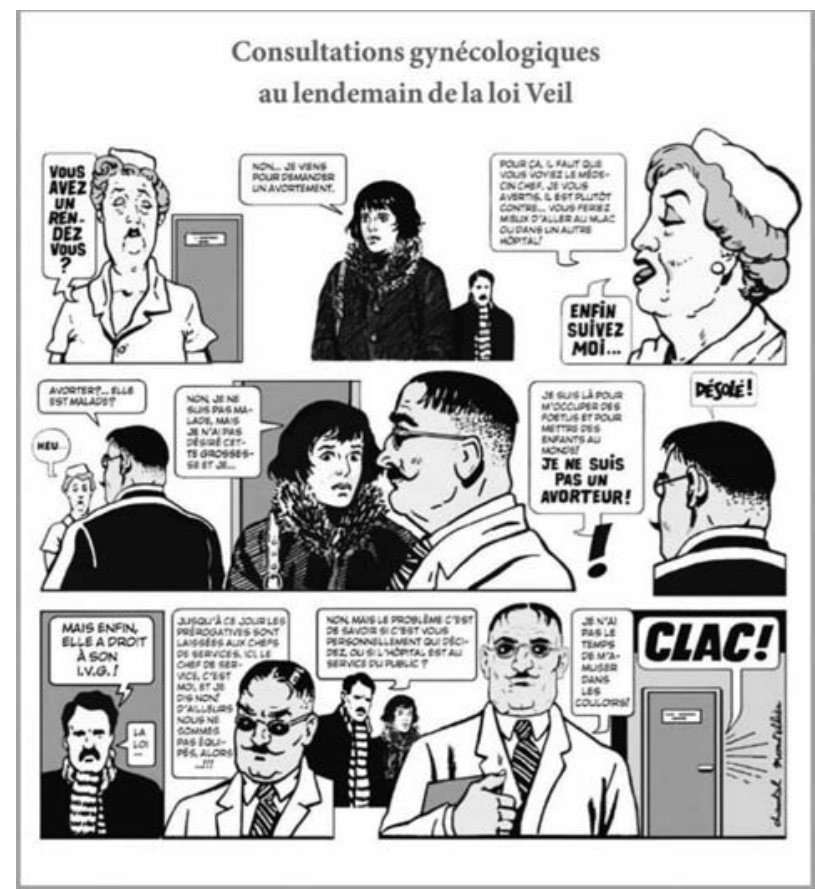

Figura 1. Primera historieta política de Montellier, publicada en L'Unité

La primera incursión en la industria del cómic llegó con su primera publicación en 1974 en Charlie Mensuel ${ }^{3}$, aunque para la misma Montellier el acontecimiento fundacional parece ser su posterior participación en la revista Ah!nana, ya que como afirma en una entrevista de 2009 " [s]i Anne Delobel, coloriste de Jacques Tardi et secrétaire d'Ah Nana [sic] n'était pas venue me chercher je ne serais jamais devenue auteur de bande dessinée" (Boy, 2009, p. 6).

Cabe destacar que Montellier tiene un recorrido profesional atípico y que a diferencia de otros autores de los años 70, como por ejemplo Claire Brétecher, irrumpirá en el cómic haciendo directamente cómic adulto en el momento de consolidación de éste, sin haber pasado antes por el cómic infantil. Este no es un hecho secundario, puesto que muestra como ya desde sus inicios Montellier tiene claro se inscribe dentro de una "lógica de información y compromiso" y no dentro un cómic concebido para el entretenimiento (Boy, 2009, p. 25) y mantendrá esta adscripción a lo largo de toda su carrera, sin hacer ninguna concesión a este último.

No podemos obviar que en esos momentos, los años 70, la industria del cómic en Francia, ya fuese para público infantil o adulto, vivía la edad de oro de las revistas de cómic. Los autores publicaban en éstas y las series que tenían más éxito se publicaban posteriormente 
en formato álbum, generalmente en la editorial que alojaba la cabecera de la revista. Así, tanto Ah!Nana como Métal Hurlant, ambas revistas propiedad de la editorial Les Humanoïdes Associés, publican las historietas de Andy Gang, un policía de Marsella corrupto, violento y machista: el estereotipo del macho. No deja de ser significativo que Chantal Montellier, quien destaca por tener personajes femeninos fuertes en sus cómics, en los primeros optase por un protagonista masculino.

Chantal Montellier también publicará a partir de 1978 en ( À Suivre), en la que aparecerá la serie protagonizada por una de sus protagonistas más emblemáticas, Julie Bristol, y que luego será recopilada en diversos álbumes. Julie Bristol es una mujer fuerte, inteligente e independiente que realiza documentales sobre artistas olvidadas, como la escultora Camille Claudel (La fosse aux serpents, 1990) y la pintora Artémisia Gentileschi (Faux sanglant, 1992). Aquí nos encontramos con un claro posicionamiento reivindicador de Montellier y en una elección clarividente de personaje protagonista, ya que la recuperación de figuras femeninas olvidadas a través de la investigación ha sido llevada a cabo casi exclusivamente por mujeres.

Chantal Montellier es conocida por haberse inspirado en las noticias de sucesos (los fait divers) para crear algunos de sus cómics, como por ejemplo la serie Andy Gang. Pero ésta no es la única, en el álbum Blues (1979) estos sucesos se cuentan desde el punto de vista de la víctima, ocupando cada uno de ellos una página del cómic. En muchos de los casos retratados, la víctima y el verdugo se confunden, para acabar siendo en cualquier caso la víctima de una sociedad opresora y deshumanizada. El álbum presenta ya la estética fría y distante que será característica de la obra de Chantal Montellier, a medida que nos alejamos de su estilo inicial, más próximo a Tardi.

En 1984 Chantal Montellier publica Odile et les crocodiles, un cómic de denuncia claramente feminista y en el que aparece Odile, otro de sus personajes más logrados. Odile es actriz y sufre una violación múltiple a la salida de una actuación cuando se dirige a buscar su coche en el aparcamiento. Tras ésta, ella busca su recuperación yendo a un psicoanalista, quien intentará convencerla de que es ella quien de forma inconsciente ha provocado la violación, y por tanto la responsable de la misma, y le propone que para recuperarse reemprenda lo antes posible la actividad sexual, acostándose con él, por ejemplo. Odile, llena de ira, reacciona matándolo. A partir de ahí, cada noche saldrá a la búsqueda (no muy complicada, por cierto) de depredadores sexuales, los cocodrilos, que se encuentran por todas partes, como una forma de vengarse de los hombres en general en una cultura patriarcal y de la violación. El discurso de Montellier en el conjunto de su obra, pero expresado de forma más evidente en Odile et les crocodiles, entronca con el de Colette Guillaumin, para quien tanto la violación como el acoso sexual son la consecuencia de la asunción por parte de la sociedad de la "pertenencia de la clase de las mujeres en su totalidad a la clase de los hombres en su totalidad” (Puleo, 2005, p. 45).

A partir del cambio de siglo y tras una década de silencio, Chantal Montellier regresa al cómic y realiza dos de sus obras principales, en las que adopta la forma de investigación periodística. Les Damnés de Nanterre (2005) procede de un encargo de Jean-Luc Fromental, editor de Denoël Graphic, a Chantal Montellier para que narrase el caso Rey-Turpin en el que una pareja de jóvenes estudiantes universitarios y sin antecedentes cometen en 1994 un atraco que deriva en persecución, toma de rehenes y tiroteo en plena calle del 
centro de París con varias personas muertas, entre ellas policías. Este hecho, así como una de sus protagonistas, Florence Rey, tuvo un gran impacto en la sociedad francesa en su momento y recibió un amplio seguimiento mediático ${ }^{4}$. La investigación que lleva a cabo Chantal Montellier para realizar el álbum la lleva a conclusiones que van más allá de la versión oficial sobre el asunto. Tchernobyl mon amour $(2006)^{5}$ trata sobre el desastre nuclear homónimo, desde la perspectiva de la irresponsabilidad política y las mentiras de los responsables de los diferentes países afectados y el tributo y reconocimiento por la extraordinaria labor y la denuncia al trato ignominioso que recibieron los miles de hombres que sacrificados sus vidas para evitar que el desastre tuviese mayores consecuencias: los liquidadores.

De ambos álbumes, a parte de su contenido político, su cambio en la forma narrativa más cercana al periodismo y una propuesta gráfica más arriesgada con múltiples capas de contenido y en la que es habitual el uso simbólico de las imágenes, a años luz del estilo clásico de sus primeros álbumes, cabe destacar la aparición de un nuevo personaje femenino fuerte, la periodista Chris Winckler.

Hemos mencionado ya a los tres personajes femeninos más destacados de Chantal Montellier: Julie Bristol, Odile y Chris Winckler. Los tres representan un recorrido. Julie, personaje sin duda fuerte ya que se trata de una profesional que recorre el mundo para documentarse para sus documentales sobre mujeres, gráficamente se circunscribe dentro del estilo clásico de la bande dessinée con clara influencia gráfica de las mujeres de Jacques Tardi y Crepax. Aunque no se trata de un personaje especialmente sexualizado, aún está cerca de la representación tradicional femenina, de corte más sensual. Por el contrario, la representación gráfica de Odile, más estilizada y fría, asexuada y en absoluto erótica, deja ya entrever el camino hacia la construcción del personaje de Chris Winckler, también una profesional liberal, una periodista, que aunará en ella las dimensiones intelectual y onírica de la obra de Crepax.

A propósito de sus personajes, la misma Chantal Montellier los define del siguiente modo, dejando de manifiesto que su representación no es accidental y que, por lo tanto, también es política:

J'essaie de fabriquer un personnage avec lequel je puisse vivre agréablement le temps d'un álbum, ou de plusieurs. Des personnages de jeunes femmes d'aujourd'hui, ni trop jolies ni trop laides. Suffisamment actives et se servant à la fois de leur jambes et de leur têtes. Elles ont un petit côte androgyne, leur féminité est discrète... Je n'étale pas leur attributs, au risque de perdre des lecteurs... Ce sont généralement des trentenaires, un peu intelllos, un peu artistes, un peu de gauche, un peu féministes, et très déterminés. Elles aiment le riques et n'ont pas peur du feu. Pas assez. Ceci étant, je ne les construis pas de cette manière avec la volonté délibérée de "countourner les stéréotypes", mais parce qu'elles me plaisent ainsi. Si je crée un nouveau type d'hérö̈nes que les habituelles accompagnatrices de héros, ou les blondes à gros nichons et cervelles d'huître, tant mieux (Boy, 2009, p. 11).

Sin embargo, ni Tardi ni Crepax serán las únicas influencias de Chantal Montellier. La de Nicole Claveloux es reconocida por la misma Montellier en primer lugar y no es nada des- 


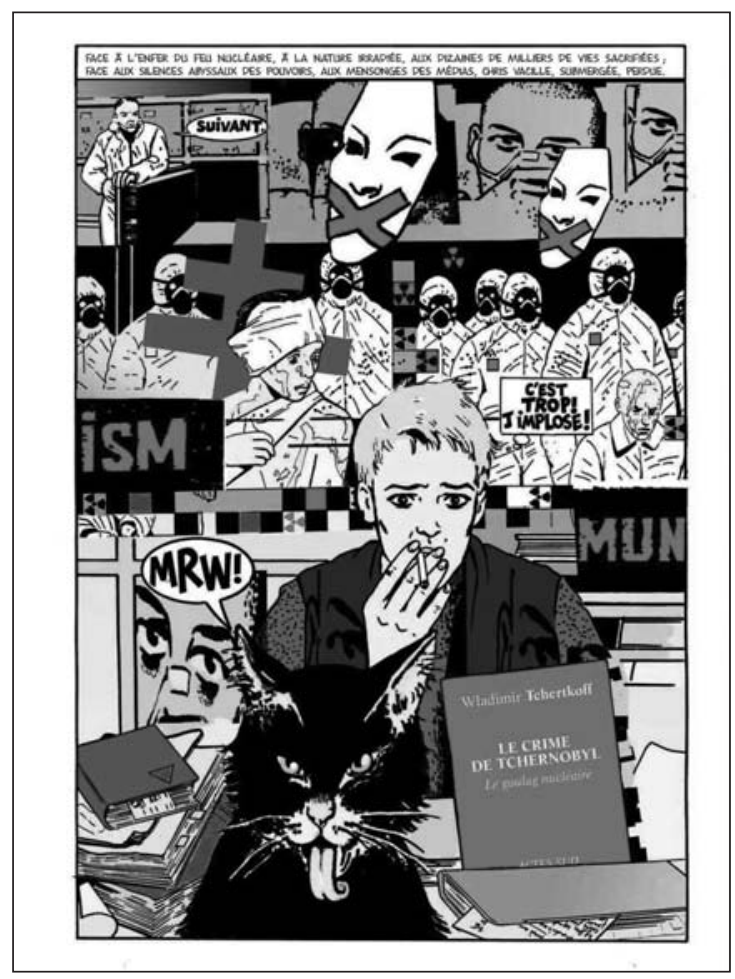

Figura 2. Página interior de Tchernobyl mon amour.

preciable la del grupo Bazooka ${ }^{6}$ en su estilo gráfico. En la composición de página de obras como Tchernobyl mon amour podemos entrever, aunque lejana en el tiempo, la influencia del grupo Bazooka (ver figura 2).

Reducir la obra de Chantal Montellier a su carácter feminista sería una simplificación empobrecedora que no haría justicia a su vocación real. Más exacta sería la definición de Thierry Groensteen según la cual la obra de Montellier es una "croisade contre tous les mécanismes d'oppression et d'aliénation du citoyen, de la femme et de l'artiste" (1996). En efecto, si bien es innegable el compromiso feminista de Montellier en sus obras, más explícito en unas (Odile et les crocodiles, Sorcières mes soeurs, La fosse aux serpents, Faux sanglant...), más secundario en otras (Shelter, Tchernobyl mon amour, L’inscription...), y que en sus obras se tratan temas como las relaciones de poder entre hombres y mujeres, la violación, la independencia de la mujer, el machismo, la utilización de sus cuerpos, etc.; en realidad Chantal Montellier ha centrado su obra en denunciar la deshumanización, esto es, todas las formas de explotación de un individuo sobre otro, siendo quizá la del hombre sobre la mujer la que aparece más a menudo, pero no la única. 
Que la deshumanización es su tema principal, su objeto de interés y denuncia, es sin duda la razón por la que ha utilizado la distopía como recurso en algunas de sus obras (como por ejemplo 1996, Shelter o Wonder $C_{i t y}{ }^{7}$ ), para reflejar su visión pesimista de la humanidad. En estos tres álbumes Chantal Montellier nos muestra cuerpos femeninos serializados (y por lo tanto intercambiables), a menudo recordando la estética del sadomasoquismo (un reflejo de la sociedad y cultura patriarcal) y nos advierte del peligro del fascismo y de sus mecanismos de control del ciudadano, de la eugenesia, el sexismo y del sacrificio de la libertad en aras de la seguridad o de la supervivencia (Cortijo, 2016).

En resumen, la obra de Chantal Montellier se inscribe dentro de lo que hoy conocemos como interseccionalidad ${ }^{8}$, esto es, las diferentes formas de discriminación y dominación que de forma simultánea se producen en la sociedad y son ejercidas sobre los individuos. A menudo, los personajes de Chantal Montellier no sólo son dominados por cuestión de género, sino también por su clase social, o su estado mental. Un ejemplo lo encontramos en la obra L'Inscription (2011), en la que una joven artista que vive en una situación de precariedad económica y hasta un cierto punto psíquica quiere inscribirse en la realidad porque se siente fuera de ésta. El proceso de inscripción en la realidad, altamente burocratizado e invasivo con la dignidad de la persona, la somete a diversos episodios de dominación altamente denigrantes en los que se conjuga su condición de mujer, artista, su precaria situación económica y la fragilidad de su personalidad. Es más, ¿no es significativo que una autora con un discurso tan personal, en una de sus escasas obras en que no es también la guionista, sino que realiza una adaptación al cómic de una obra literaria, sea ésta El proceso, de Franz Kafka, tal vez uno de los autores que más ha insistido en la despersonalización del individuo?

\section{El meteorito: la revista Ah!nana}

Chantal Montellier no fue la única autora de los años 70 en tener una visión muy crítica del trato que recibía la mujer en la industria del cómic. Recordemos que en ese momento las revistas de cómic adulto en Francia están en plena ebullición (Charlie Mensuel, L'Écho des Savanes, Fluide Glacial, Métal Hurlant, Circus...) y se está viviendo también el momento álgido del Mouvement de Libération des Femmes y el feminismo de la segunda ola, el cual politizó las cuestiones sexuales (recordemos afirmaciones como "lo personal es político" (Hanisch, 1970) y la eclosión de múltiples revistas que recogían el mensaje feminista como Le Torchon brûle, Les Cahiers du GRIF, Le Quotidien des femmes, Les Nouvelles féministes, Glife Informations, Femmes-Information, Les Pétroleuses o L'Information des femmes... (Cortijo, 2016).

Es ésta una época de compromiso y de posibilidades, en la que también se está viviendo la eclosión del cómic adulto, aunque las autoras de cómic no parecen tener cabida en él. En este contexto un grupo de autoras reacciona al contenido manifiestamente sexual y machista de la revista Métal Hurlant ${ }^{9}$ (aunque no sea la única que le asigna a la mujer un trato vejatorio) y deciden recoger el guante que les lanza el director de Métal Hurlant, Jean-Pierre Dionnet, de crear ellas una revista de cómic (Delaborde, 2006). Ah!nana, 
creada "par et pour les femmes" ${ }^{10}$, será albergada por la misma casa editorial que Métal Hurlant, Les Humanoïdes Associés.

La misma Chantal Montellier explica la situación de las autoras de cómic en ese momento y las razones que llevaron al surgimiento de esta revista:

On voulait notre support car à l'époque, il était vraiment très difficile de publier pour une femme. Il y avait des résistances plus ou moins conscientes de la part du milieu de la BD quasi exclusivement masculin. Tout reposait sur un système de reconnaissance dans lequel les femmes n'entraient pas. Fatalement, certaines devaient se cantonner au dessin pour enfant et les rares femmes qui arrivaient à publier dans des journaux BD n'étaient même pas admises en conférences de rédaction ${ }^{11}$ (Bodoï, 2000).

Ah!Nana, de periodicidad trimestral y dirigida por Janic Guillerez, tiene como modelos la antología de cómic underground estadounidense Wimmin's Comix (1972-1992)12 y la revista Sorcières ${ }^{13}$ (1976-1981), de tendencia política y psicoanalítica (Cortijo, 2016). Ah!Nana tiene una doble vocación, ser una revista de cómic y de actualidad, que dé voz a autoras de cómic y a mujeres periodistas. El núcleo duro de autoras que participan está conformado por la misma Chantal Montellier, Florence Cestac, Olivia Clavel, Keleck, Nicole Claveloux, Cecilia Capuana ${ }^{14}$, y también publicarán a representantes del underground norteamericano como Trina Robbins y Sharon Rudalh, en lo que no puede dejar de interpretarse como un reconocimiento o hermanamiento con una experiencia anterior $y$ relativamente similar en los EE. UU., el Wimmen's Comix Collective. Los autores tendrán presencia ocasional, adaptándose al tono y contenido de la revista, como Moebius, Chaland y Tardi, y a menudo firmarán con un pseudónimo femenino.

El primer número de Ah!Nana se publica en octubre de 1976. Desde un principio adopta un tono satírico y provocador, y quizá con el ánimo de recuperar todo aquello que no se ha hecho o dicho hasta el momento, pecó por exceso. A modo de declaración de intenciones, la portada del primer número, de Keleck, es una escena de striptease con una evidente inversión de roles. Es el hombre quien se desnuda en el escenario y ellas el público expectante y alborotado. La inversión de roles y la cosificación del hombre volverá a aparecer, por ejemplo, en la contraportada del número 5, de la mano de Chantal Montellier, en la representación del hombre (al que se dedica el número) como conejito (Ver Figura 3), muy maquillado, con sonrisa estúpida y poses provocativas. La inversión de roles es una crítica radical al patriarcado. Kate Millett afirmaba que la mujer había padecido la construcción patriarcal del deseo y del objeto del mismo (1969), por lo que la inversión debía ser considerada como un ataque a uno de los pilares constitutivos de la sociedad.

La mitificación de la maternidad y del rol de la madre amorosa y la visión del embarazo como un estado ideal (también resultado de la ideología patriarcal que pone el acento en los roles tradicionalmente asignados a la mujer en la sociedad burguesa) son combatidos a menudo en la revista. Por ejemplo, la contraportada del primer número (ver Figura 4), también de Keleck al igual que la portada como ya hemos visto, nos muestra en Voici l'enfant un parto con toda su crudeza, huyendo de la imagen idealizada y pudorosa del mismo, y la reanimación brutal del bebé con la enfermera pisándolo con tacones de aguja 

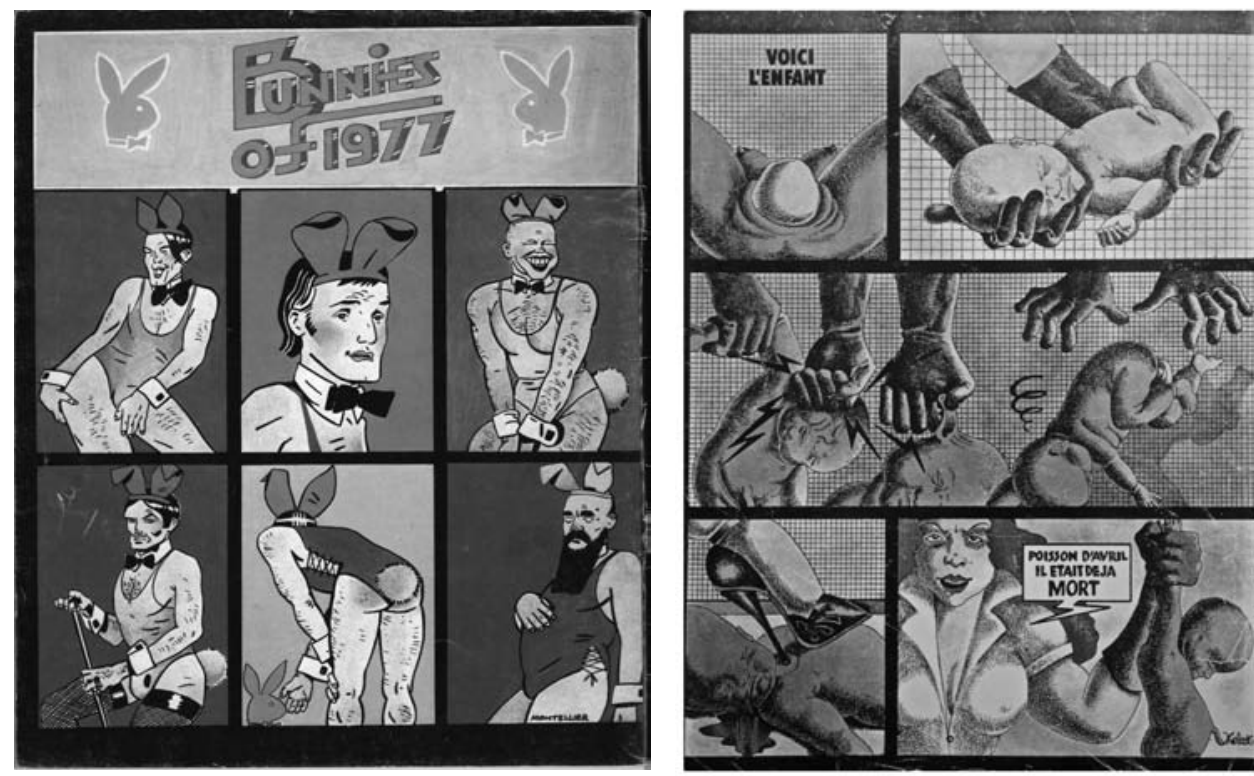

3

4

Figura 3. Contraportada de Chantal Montellier. Figura 4. Contraportada del número 1 de Ah!nana, por Keleck.

(transposición de una imagen icónica del sadomasoquismo) en lugar de darle la tradicional palmadita en el trasero, para acabar con la enfermera diciendo "poison d'avril, il était déjà mort" ${ }^{15}$. En esta contraportada provocadora de Keleck, se está "negando la principal función materna, en la tradición burguesa, de la mujer "comme il faut" (Cortijo, 2016, p. 152) y se utiliza la estética de una de las fantasías sexuales de la sociedad patriarcal para atacar uno de los mitos en los que ésta se fundamenta.

En el número 3, una historieta de trazos mínimos de una sola página de Aline Isserman, en la que se representa a dos amigas hablando y a la hija de una de ellas sentada en el suelo jugando y escuchando la conversación de las adultas, a medida que se va estremeciendo horrorizada, muestra un diálogo en que una madre describe de manera franca todo el impacto negativo que ha tenido la maternidad en su vida: la pérdida de la salud, los vómitos del embarazo, la falta de calidez y consideración en el hospital, el parto con fórceps, la cesárea final. Una descripción de toda aquella realidad que el relato oficial edulcorado del embarazo oculta a las mujeres.

Otro tema recurrente es la relación de la mujer con la sexualidad. De hecho, la tematización sexual es una de las manifestaciones del feminismo radical. A la mujer se la representa sexuada y demandante. Una mujer que es sujeto de placer y que está cómoda con su cuer- 
po y con su sexualidad y adopta una actitud proactiva y activa en relación con el hombre para la obtención de placer. No es ella la que está sometida a los deseos del hombre o a la imagen o concepción de la sexualidad de éste como estábamos acostumbradas a ver en los cómics de la época, fuesen o no eróticos, sino que ella misma define las reglas del juego y reclama su propio placer. La historieta La vengeance de peau blanche, de la norteamericana Trina Robbins publicada en el número 2, tiene todos los componentes de la típica historieta que refleja las fantasías sexuales del hombre. En ella una rubia explosiva es secuestrada y sometida a todo un conjunto de vejaciones sadomasoquistas por un indio (taureau furieux), que para vengarse de las humillaciones que ha sufrido su tribu por los blancos, obliga a una representante de estos, la protagonista, a realizarle entre otras cosas una felación. Al final de la historieta y en un giro sorprendente, cuando ésta tiene la oportunidad de salvarse y de vengarse del indio, lo que le pide como venganza es el pago de la misma moneda a la inversa, es decir, que él le haga a ella un cunnilingus, en el cual ella parece disfrutar de lo lindo.

Nicole Claveloux publicó en todos los números de la revista. Sus historietas destacan por su virtuosismo gráfico dentro de un plantel que no estaba mayoritariamente formado por autoras profesionales. Claveloux, cuya carrera ha sido un viaje de ida y vuelta de la ilustración infantil al cómic, realiza reinterpretaciones de cuentos y personajes tradicionales a la luz del feminismo. Así, por ejemplo, el de Blancanieves, en este caso Planche-Neige (núm. 3), con una reina obesa que le pregunta al espejo quién es la más delgada y cuya protagonista acaba siendo la criada de la casa del ogro y sus siete hijas. O el de La conasse et le prince charmant (núm. 2), una burla cruel sobre las expectativas que nos impone a las mujeres nuestra educación sentimental. En ésta una mujer espera la llegada del príncipe azul desde el día de su nacimiento. Y se le pasa la vida en la espera, para llegar éste, bastante desmejorado, por cierto, cuando ella está celebrando ya sin esperarlo su 94 cumpleaños y de la impresión que tiene al verlo sufre un infarto. En la actualidad la breve obra historietística de Claveloux está siendo objeto de recuperación por parte de la editorial Cornélius y ha recibido el premio al patrimonio por La main verte et autres récits ${ }^{16}$ (2019) y el honorífico a toda su carrera, durante el pasado Festival International de la Bande Dessinée de Angoulême 2020.

Tal como afirma Cortijo en relación a las autoras que participaron en Ah!Nana, en "las publicaciones de estas pioneras, el cuerpo desnudo, su control, su manipulación, su sexualización, son motivo de reivindicación de espacios que hasta ese momento, habían sido monopolizados por los autores" (2016, p. 163). La historieta Visite inattendue, de la italiana Cecilia Capuana, publicada en el número 3 de la revista, representa a la mujer como elemento subversivo del orden burgués y patricarcal establecido (ver Figura 5). Es la mujer en su rotunda y esplendorosa desnudez que se muestra poderosa y dueña de sí misma; no en vano la postura del cuerpo desnudo de la mujer recuerda las representaciones de las mujeres míticas de Botticelli. Es ésta una concepción y una demostración de poder por parte de la mujer que la sociedad (representada en la historieta por unos ancianos retrógrados y miedicas) no puede tolerar y que la destruye. 


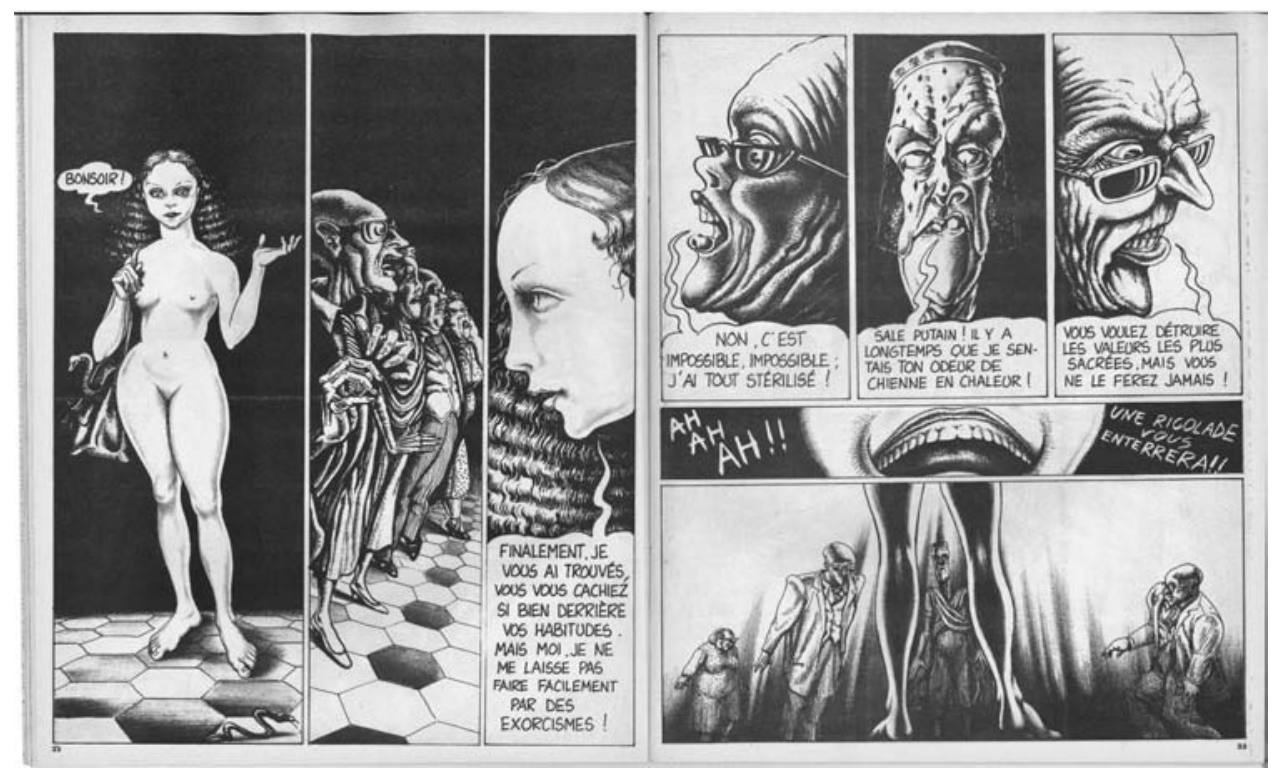

Figura 5. Dos páginas de la historieta Visite inattendue, de Cecilia Capuana.

Como hemos podido ver, tanto los temas tratados como el tratamiento recibido tienen afán de provocación y subvierten los fundamentos de la sociedad en lo que respecta al trato de género. Siguiendo los postulados de la segunda ola del movimiento feminista, las historietas de Ah!nana sacan a la luz cuestiones que hasta ese momento formaban parte de la esfera privada, esto es la maternidad, el deseo femenino, el cuerpo en lo que tiene que ver con el empoderamiento, la violencia ejercida por el hombre sobre la mujer, etc.; y revierte papeles poniendo al hombre en situaciones en las que hasta entonces sólo había estado la mujer y que se consideraban naturales. Todo lo anteriormente citado debió de generar una gran incomodidad, por parte de los detentadores del poder, ya fuese tanto social como en la industria del cómic. La reacción, tal como veremos más adelante, no tardó en llegar. A partir del cuarto número (abril de 1977), cada uno de ellos es un monográfico sobre temas controvertidos (ver Figura 6) como el nazismo, la moda, la sexualidad infantil o el sadomasoquismo. Será justamente el octavo número, dedicado a la homosexualidad, con el que la revista es censurada y prohibida su venta a menores de edad (cuando ésta era una revista para adultos) por considerarse su contenido obsceno. En concreto, la prohibición se lleva a cabo el 18 de julio de 1978 por la Commission de surveillance et de contrôle des publications destinées à la jeunesse (creada por una ley con fecha de 16 de julio de 1949) ${ }^{17}$. Con la prohibición de su venta a menores, ésta dejará de poderse vender en quioscos, 

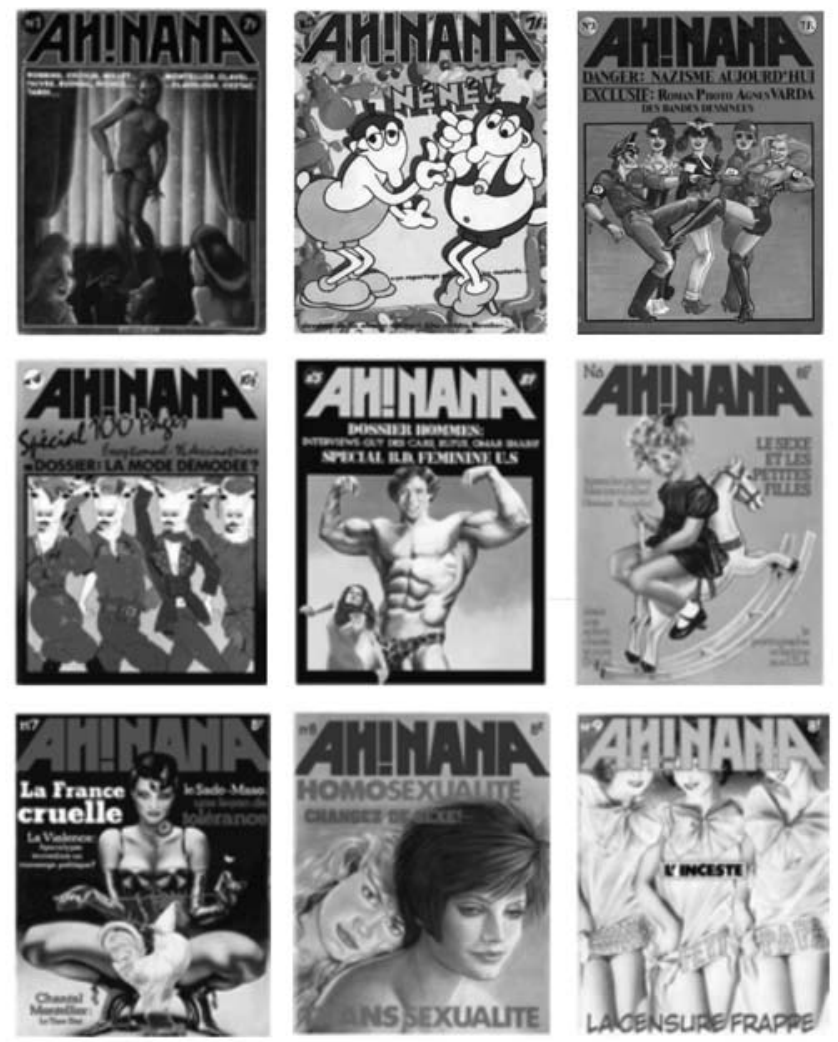

Figura 6. Portadas de los 9 números de Ah!nana.

estaciones de trenes, etc.; y por lo tanto se la condena a una muerte comercial, que muy probablemente se hubiese producido igualmente, porque sus ventas eran bajas, pero no tan rápido. Aún así, todavía se publicará un último número, el noveno, en septiembre de 1978, consagrado al incesto.

El equipo de la revista interpretó esta censura como una reacción del patriarcado contra una publicación libre creada por mujeres que cuestionaba el orden establecido. Chantal Montellier afirma en su autobiografía a este respecto:

Ainsi disparut la première et dernière revue de bandes dessinées féminines en France, une de trop? Tuée pour une pornographie qu'elle ne contenait pas malgré certaines accroches un peu trop racoleuses. En revanche, les kiosques étaient, eux (et sont toujours), de véritables officines pornos et, dans des revues comme L'Écho des savanes ou Hara Kiri (pour ne citer qu'elles), pornographie et vulgarité pouvaient s'étaler en toute liberté. Deux poids, deux mesures? (2015, p. 209).

Del plantel de autoras europeas que formaron parte de la experiencia de Ah!nana, sólo Florence Cestac y Chantal Montellier siguieron en el cómic. Nicole Claveloux regresó al álbum infantil y otras, como Keleck, cayeron en el olvido. 


\section{Los asteroides}

A la hora de analizar su legado, tanto el de Ah!nana como el de Montellier, apenas podríamos encontrar autoras que hayan seguido su estela. La misma Chantal Montellier es muy crítica con la producción que están realizando las mujeres autoras de cómic en la actualidad:

J'avoue avoir été légèrement déçue parce que j'ai pu voir pendant ces deux années d'existence du Prix Artémisia, par la bande dessinée féminine. (...) le côté nombriliste qui prédomine constitue un repli sur le premier cercle, la famille, l'organique, le giron natural. (...) La politique, elle, s'absente quasi totalement. Donc, en gros, plus de femmes s'expriment et sont publiées, mais pour mieux revenir à ce qui est depuis toujours considéré comme leur territoire assigné : la maison, l'intime. En cela, la bande dessinée féminine actuelle participe, volontairement ou pas, à un retour à "l'ordre", et pas que symbolique (Boy, 2009, p. 15).

En efecto, si bien es incuestionable que el número de autoras de cómic ha aumentado notablemente, la producción femenina actual tiene un conjunto de temas predominantes como las conocidas como narrativas del trauma (Debbie Drechsler, Phoebe Gloeckner), las relaciones con el padre o la madre (Alison Bechdel), el descubrimiento de la homosexualidad (Alison Bechdel, Julie Maroh), la situación de la mujer a partir de la microhistoria (Marjane Satrapi, Marguerite Abouet, Fumiyo Kouno), las relaciones con hermanos y hermanas (Rachel Deville), con la famila extensa (Joana Hellgren, Zeina Abirached), la enfermedad y la senectud (Judith Vanistendael) o la biografía de mujeres relevantes (Catel, Hinako Sigiura, Mary Talbot) (Terrones, 2019).

Algunas de estas obras sí que tienen un discurso feminista en su génesis (pienso en las obras de Catel o de Mary Talbot), pero son pocas las que aúnan el discurso feminista con un cierto discurso político, es decir, obras políticas que denuncian la opresión por razón de género de la mujer por parte del hombre o de la sociedad patriarcal; y que lo hacen adoptando unas formas discursivas que rehúyen las formas y discursos que se permiten y se esperan de las mujeres autoras de cómic. La industria editorial del cómic, como cualquier otra industria, tiene un extraordinario poder para delimitar y marcar qué es lo que se espera de una autora de cómic:

En effet la femme lambda qui parle de son quotidien et de ses astuces beautés, qui est une accro à la mode et au régime décomplexe, qui est blanche et sans autres problèmes que ses déboires sentimentaux et qui n'émet aucune critique sur la société qui ne valorise pas les femmes. (...)Et cela devient particulièrement vicieux dans le monde du travail lorsque les critiques et éditeurs sollicitent un "caractère feminin" (...) Il y a cette idée que même dans l'Art, avec ton travail, en tant que femme, tu dois plaire, tu dois correspondre à la femme (Motais, 2016, p. 246).

Dos son las principales excepciones, aunque no las únicas ${ }^{18}$. Liv Strömquist y Ulli Lust, curiosamente dos autoras del centro y del norte de Europa, pero en ningún caso de la 
Europa del sur, las que han desarrollado un discurso feminista con componente político y, por lo tanto, incómodo, además de no pretender en ningún caso realizar un cómic bonito. Liv Strömquist hasta el momento tiene sólo dos títulos publicados en España: Los sentimientos del príncipe Carlos (2010) y El fruto prohibido ${ }^{19}$ (2014). El primero es una historia cultural del amor romántico y el segundo de la vagina. Ambos tienen carga política tanto por el fondo como por la forma. En efecto, el género seleccionado, el ensayo, es decir, el discurso argumentativo estructurado a partir de la razón, ha sido tradicionalmente un género asociado al hombre, tanto en lo que respecta a la autoría como al lectorado, justamente por disfrutar éste del monopolio de la razón por parte de la sociedad patriarcal, a diferencia de la mujer, más "dotada" para el discurso emocional e intuitivo. Strömquist hace un recorrido argumentado sobre la apropiación masculina de la representación y no representación de la vagina, desposeyendo a la mujer de la titularidad de su órgano sexual y de su relación con éste. Además, y a vueltas otra vez con la forma, Strömquist no tiene la más mínima intención de que su discurso sea bonito (el tono es directo, irónico y hasta sarcástico, cualquier cosa menos suave) y el dibujo no pretende en absoluto ser bonito. Stömquist rehúye lo que se espera de ella como autora de cómic, siendo ésta ya una declaración política.

Tal como ya hemos visto en el caso de Ah!nana, la utilización de las herramientas y recursos de la sociedad patriarcal para hacer un discurso contrario a ésta tiene un componente altamente subversivo justamente por su eficacia. Liv Strömquist parece saberlo y no duda en utilizarlo.

Más tradicional cuanto a la forma y fondo del discurso es la obra de Ulli Lust, Hoy es el último día del resto de tu vida ${ }^{20}$ (2009). Sin embargo probablemente sea hasta ahora la que mejor ha denunciado las enfermizas relaciones desiguales de poder entre hombres y mujeres en el seno de la sociedad patriarcal. De corte autobiográfico, la obra narra el viaje que en 1984 Ulli y su amiga Edi, dos jovencísimas punks austriacas realizan a Italia sin documentación y sin más equipaje que lo puesto y un saco de dormir. Durante los dos meses que durará este, y a medida que se acercan al sur de Italia, el viaje se convierte en un descenso a los infiernos, en el que Ulli padecerá el machismo, el acoso sexual, las agresiones sexuales y las violaciones toleradas por una sociedad machista que vulnera sus derechos como ser humano. La protagonista sin dinero, pronto se dará cuenta de que siendo amable ante los requerimientos de los hombres y comercializando con su cuerpo es fácil obtener dinero. La situación de precariedad económica y el hecho de estar en el país de forma irregular ${ }^{21} \mathrm{y}$ viviendo en la calle, la convierten en una presa especialmente vulnerable al abuso de poder de tipo sexual. Sus problemas aumentarán cuando se encuentre totalmente sola, ya no esté dispuesta a vender su cuerpo y observe como el "no" no se considera una opción.

Hoy es el último día de tu vida demuestra que "[a] unque suele recurrir a la fuerza (violaciones, excisión, prohibición del aborto, prostitución, reclusión, velo, etc.), el patriarcado se apoya sobre todo en el consenso generado por la socialización de género" (Puleo, 2005, p. 52). En su deambular solitario por las calles de Palermo, sucia y despeinada, Ulli no sólo no encuentra solidaridad por parte de los hombres, si no que las mismas mujeres la miran con desprecio. La situación de desigualdad que vive Ulli con respecto al hombre atenta contra su integridad física, psíquica y sexual y esta desigualdad se perpetua a través de un 

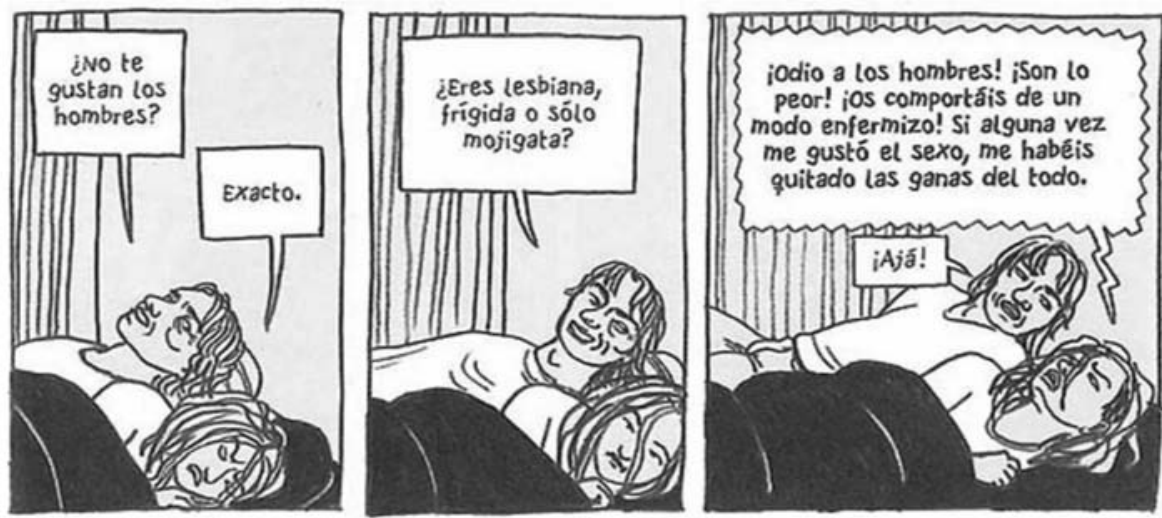

Figura 7. Viñetas interiores de Hoy es el último día del resto de tu vida, de Ulli Lust.

constructo ideológico que libera al hombre de toda responsabilidad, ya que es la mujer, que no sabe cuidar de ella misma, la culpable de sufrir una violación por exponerse a un peligro del que tenía que haberse protegido ella misma. La culpable de la violación es la mujer por su imprudencia (y por haber tenido la soberbia de creer que podía disfrutar de la misma libertad de movimientos que el hombre), no el hombre que comete el acto.

En la Figura 7 observamos la ideología que se esconde detrás de algunas expresiones que, además de descubrir otros tipos de conductas, también representan una agresión a las mujeres.

Ulli está compartiendo cama con Andreas, un amigo, con el que no tiene ningún tipo de relación sentimental ni física. Andreas, al igual que pasa con muchos de los hombres con los que Ulli se cruza a lo largo de la obra, interpreta la situación de soledad en compañía de Ulli como una invitación a mantener relaciones sexuales. Ulli se niega y la respuesta de Andreas ante la negativa (bastante moderada en comparación con otras que se ven a lo largo del cómic) es la que reproducen las tres viñetas. De ellas inferimos, además de lo citado, que si una mujer no acepta mantener relaciones sexuales con un hombre tiene que ser lesbiana o tener algún otro tipo de tara o defecto físico o de carácter ("frígida" o "mojigata") y que el hombre concibe a la mujer como un simple objeto para satisfacer sus pulsiones, no teniendo ésta otro papel más que el de la sumisión, y si no es así, es una mujer "defectuosa", con la consecuente inoculación de un sentimiento de culpabilidad y/o inadecuación, que la presiona psicológicamente y la hace sentir vulnerable. 


\section{Conclusiones}

A lo largo del presente artículo hemos demostrado el compromiso evidente de Montellier con el feminismo, el cual se manifiesta en su obra de formas variadas y consistentes a lo largo del tiempo en aspectos como la selección de sus protagonistas, los temas tratados y el discurso seleccionado, la representación de la mujer, etc. Este compromiso ha sido mantenido aún cuando el feminismo dejó de ser una ideología popular, por lo que la fidelidad a la ideología impregna la obra de Montellier. Ésta, a partir de lo que conocemos como interseccionalidad, muestra los diferentes niveles de opresión que padecen las personas, siendo éste el hilo vertebrador de una trayectoria única, excepcional e incomprendida.

La revista $A h ! n a n a$, incluye en sus páginas muchos de los postulados del feminismo radical de la segunda ola, ya sea tematizando la sexualidad, dando protagonismo al cuerpo de las mujeres y a su relación con el mismo y sacando a la luz pública las relaciones de desigualdad que tienen lugar en la esfera privada. Es desafío que representó para el patriarcado la toma de poder simbólico que se ejercía dentro de la revista y la subversión de los roles establecidos que estructuran la sociedad pueden ser la causa de la censura de la revista como obscena, cuando otras revistas de cómic casi pornográficas no tuvieron problemas para seguir comercializándose con normalidad.

Ambas experiencias, pueden calificarse como únicas, puesto que en su origen tienen la vinculación del discurso feminista con el político, hecho casi excepcional en la actualidad. En efecto, hay más mujeres dibujantes, pero éstas siguen, muchas sin saberlo, la lógica patriarcal. Destacamos la figura de dos autoras que a pesar de la diferencia siguen esta línea que aúna el feminismo desde el posicionamiento político: Liv Strömquist y Ulli Lust.

\section{Notas}

1. Asociación fundada en 2007 por Chantal Montellier, Jeane Puchol, Marie-Jo Bonnet, Marie Moinard, Anne Bleuzen y Sylvie Fontaine, con el propósito de visibilizar el cómic creado por mujeres.

2. Estamos aquí ante un ejemplo del conocido como patriarcado de consentimiento en oposición al de coerción. En el primero, "[s]implemente se deja actuar a la inercia estructural, apenas erosionada por enfáticas políticas de igualdad” (Puleo, 2005, p. 38).

3. Fundada el 1969 por dibujantes que provenían de la satírica Hara Kiri, fue la primera revista francesa que presentó el cómic desde un punto de vista adulto (Mazur, 2014).

4. De hecho, llegaron a alzarse voces pidiendo la reinstauración de la pena de muerte, abolida en Francia en 1981.

5. Parodia el título de la película de Alain Resnais Hiroshima mon amour (1959) con guión de Marguerite Duras.

6. Este grupo, que seguía la estética punk, estuvo vigente de 1976 a 1978, surge a partir del movimiento situacionista de los años 60 y entre sus componentes se encuentra Olivia Clavel, que más tarde coincidirá con Chantal Montellier en Ah!Nana. Sus componentes publicaron en Charlie Mensuel, Métal Hurlant, L'Écho des Savanes y (À Suivre) (Mazur, 
2014). Estaban influidos por el futurismo ruso, el hiperrealismo, la estética vídeo y las imágenes de actualidad. Utilizaban el collage y el dibujo recortable y su principal influencia intelectual era el Movimiento Dada tanto por su espíritu provocador como por su voluntad de ruptura (Delaborde, 2013).

7. Publicados en formato álbum en 1978, 1980 y 1983 respectivamente.

8. Término acuñado en 1989 por la socióloga Kimberlé Crenshaw en el artículo "Demarginalizing the Intersection of Race and Sex: A Black Feminist Critique of Antidiscrimination Doctrine, Feminist Theory and Antiracist Politics", publicado en University of Chicago Legal Forum.

9. Muchas representantes del feminismo radical denunciaron "la retórica de una revolución sexual definida en términos masculinos que, en palabras de Ann Koedt, traía más carne fresca al mercado del sexo patriarcal (Puelo, 2007, p. 43).

10. Hecha por y para las mujeres.

11. Montellier hace referencia aquí a la exclusión de Claire Bretécher de las reuniones del consejo de redacción de la revista Pilote.

12. Y también It ain't me, Babe, Girl Fight Comics, All Girl Thrills y Tits and Clits (Delaborde, 2006).

13. Incluso tendrá anuncios comerciales dentro de la revista de cómic.

14. Es remarcable la ausencia de Claire Brétecher, icono del feminismo en el cómic, en una iniciativa como ésta.

15. Inocente, inocente, ya estaba muerto.

16. Recopila historietas publicadas en Ah!nana y en Métal Hurlant.

17. Legislación creada a iniciativa del Partido Comunista a raíz de la preocupación por el impacto que tenía en Francia la publicación de cómic norteamericano después de la Segunda Guerra Mundial. La ley prohíbe la publicación de contenidos destinados a niños y jóvenes que presenten de forma positiva conductas ilegales o moralmente reprobables o que "desmoralicen a los jóvenes". También prohíbe la representación de contenido violento o de tipo sexual, se dirigiesen estos o no a jóvenes y niños, que fuesen expuestos en lugares donde estos pudieran tener acceso a los primeros (Miller, 2007, p. 19).

18. Pensemos, por ejemplo, en Tanxxx.

19. Prins Charles Känsla y Kunskapens frukt.

20. Heute ist der letzte Tag vom Rest deines Lebens.

21. El acuerdo de Schengen no tendría lugar hasta 1985.

\section{Bibliografía}

Amorós, C. y de Miguel, A. (eds.) (2005). Teoría feminista: De la ilustración a la globalización, vol. 2. Del feminismo liberal a la posmodernidad. Madrid: Biblioteca Nueva.

Boy, F. (2009). Les femmes dans la bande dessinée d'auteur depuis les années 1970. Itinéraires croisés : Claire Bretécher, Chantal Montellier, Marjane Satrapi. https://dumas.ccsd.cnrs. fr/dumas-00712333 
Cortijo, A. (2016). "Mirada y representación del cuerpo femenino en el cómic francés: las autoras de Ah! Nana”: Diablotexto Digital 1. Valencia: Universitat de València, 139-167.

Delaborde, B. (2006). "Ah ! nana : les femmes humanoïdes": 9ème Art, 12. Poitiers:9e Art \& Communication.

Groensteen, T. (1996). "Une artiste militante : Chantal Montellier": Coloquio Comics as a mirror of society. Washington: Universidad de Georgetown. http://www.editionsdelan2. com/groensteen/spip.php?article18

Hanisch, C. (1970). “The Personal Is Political”: Notes from the Second Year: Women's Liberation. Nueva York: Radical Feminism, 76-78.

Macary, F. (2004). Études sur la représentation de la femme dans la bande dessinée parues en France entre 1980 et 2003. Tesis de doctorado. Lyon: Université Lyon 1.

Mazur, D. y Danner, A. (2014). Cómics. Una historia global, desde 1968 hasta hoy. Barcelona: Blume.

Miller, A. (2007). Reading Bande Dessinée. Critical Approaches to French-Language Comic Strip. Chicago: Intellect Books.

Millett, K. (1970). Sexual Politics. Nueva York: Doubleday.

Motais, B. (2016). La pilule rouge. La Femme en bande dessinée: Memoria de máster. París: École nationale supérieure des arts décoratifs.

Talet, V. (2006). "Le magazine Ah ! Nana : une épopée féministe dans un monde d'hommes ?": Clio. Histoire, femmes et sociétés. http://journals.openedition.org/clio/4562

Terrones, M. (2019). "Aspectos a tenir en cuenta a la hora de prescribir cómics creados por mujeres": BiD: textos universitarios de biblioteconomía y documentación, $\mathrm{n}^{\circ} .42$ (junio). http://bid.ub.edu/es/42/terrones.htm

VV.AA. (2000). Bodoï, 30.

Abstract: Chantal Montellier, key author of feminism in comics not only in the FrancoBelgian tradition but worldwide, has a long and coherent career as a committed author, which goes beyond her position in terms of her graphic discourse and has led her to participate in different unique initiatives. Indeed, Chantal Montellier participated in the unparalleled creation of the magazine Ah! Nana, the first and ephemeral feminist comics magazine in France in the 1970s. Montellier is also one of the founders of the Association Artémisia, the first association working spreading the comics created by women existing in Europe, which has become the source of inspiration for similar experiences in other countries. In this article we will review Montellier's artistic career and her political and feminist commitment, the unique experience of Ah! Nana and her links with the discourse of radical feminism, and we will look for the heirs of both in the current comics, in the figures of the Swedish Liv Strömquist and Germany's Ulli Lust.

Keywords: Chantal Montellier - comics - feminism - interseccionality - Ah!nana. 
Resumo: Chantal Montellier, autora fundamental do feminismo na banda desenhada, não apenas franco-belga, mas também europeia e global, tem uma carreira longa e coerente como autora comprometida, que vai além da sua posição em termos do seu discurso gráfico e que a levou a participar em diferentes iniciativas excepcionais. De fato, Chantal Montellier participou na criação da incomparável revista Ah!nana, a primeira e efêmera revista feminista de banda desenhada da França na década de 1970. Montellier também é uma das fundadoras da Association Artémisia (Associação Artemísia), a primeira associação para a difusão da banda desenhada criada por mulheres na Europa, que se tornou fonte de inspiração para experiências semelhantes em outros países. Neste artigo, revisamos o percurso artístico de Montellier e o seu compromisso político e feminista, a experiência única de Ah!nana e os seus vínculos com o discurso do feminismo radical e procuramos as herdeiras de ambos os dois na atual história da banda desenhada, nas personalidades da sueca Liv Strömquist e da alemã Ulli Lust.

Palavras chave: Chantal Montellier - quadrinhos - feminismo - interseccionalidade Ah!nana.

[Las traducciones de los abstracts fueron supervisadas por el autor de cada artículo] 